\title{
IDENTIFIKASI RADIONUKLIDA PEMANCAR GAMMA DI DAERAH PANTAI LEMAHABANG MURIA DENGAN SPEKTROMETRI GAMMA
}

\author{
Sukirno, Muzakky, Agus Taftazani \\ Puslitbang Teknologi Maju BATAN. Yogyakarta
}

\begin{abstract}
ABSTRAK
IDENTIFIKASI RADIONUKLIDA PEMANCAR GAMMA DI DAERAH PANTAI LEMAHABANG MURIA DENGAN SPEKTROMETRI GAMMA. Rencana lokasi terpilih Pusat Listrik Tenaga Nuklir (PLTN) yang akan dibangun terletak di sekitar pantai Lemahabang semenanjung Muria Jawa Tengah. Dalam rangka antisipasi kemungkinan terjadi perubahan radioaktivitas karena pembangunan PLTN, perlu dipersiapkan data awal konsentrasi radioaktiviras alami di daerah tersebut. Tujuan utama identifikasi ini dilakukan untuk mengetahui radioaktivitas gamma serta radionuklida lingkungan yang terdapat dalam cuplikan algae, ikan kerapu, sedimen dan air laut. Pengambilan cuplikan, preparasi maupun analisisnya mengacu pada prosedur analisis cuplikan radioaktivitas lingkungan. Instrumen yang digunakan adalah Maestro II EG\&G spektrometer $\gamma$ Ortec dengan detektor Ge(Li). Hasil identifikasi radionuklida alam pemancar $\gamma$ dengan teknik spektrometri $\gamma$ menunjukkan ada 6 jenis radionuklida alam yang teridentifikasi yaitu Ra-226 (186,52 keV), Pb-212 (238,75 keV), Pb-214 (395.94 keV), Tl-208 (583,19 keV), Ac-288 (911,07 keV) dan K-40 (1460,7 keV). Radioaktivitas $\gamma$ untuk semua radionuklida dalam air laut masih jauh di bawah nilai batas radioaktif lingkungan menurut SK DIRJEN BATAN No 294/DJ/1992. Radioaktifitas pemancar $\gamma$ tertinggi dalam air laut adalah K-40 terukur dengan konsentrasi 5,798 \pm 0,537 Bq/L, sedangkan konsentrasi tertinggi yang diijinkan $10^{4} \mathrm{~Bq} / \mathrm{L}$.
\end{abstract}

\section{ABSTRACT}

IDENTIFICATION OF GAMMA EMITTER RADIONUCLIDE IN THE COASTAL OF LEMAHABANG MURIA USING SPECTROMETRY GAMMA. Selected location of the planned Nuclear Power Plant (NPP) is around Lemahabang Muria peninsula Central Java. To evaluate the change of radioactivity after installation of the NPP need to be prepared data base of the natural radioactivity exposure of this area. The main objective of the measurement was carried out to know the radioactivity $\gamma$ and identification of environment radionuclides in the algae, fish, sediment and sea water. Sampling, preparation and analysis based on the procedures of environment radioactivity analysis. The instrument used for the analysis radioactivity were Maestro II EG\&G spectrometer $\gamma$ Ortec with detector $\mathrm{Ge}(\mathrm{Li})$. The $\gamma$ spectrometry technique could identify seven natural radionuclides of emitter were Ra-226 (186,52 keV), Pb-212 (238,75 keV), Pb-214 (395,94 keV), Tl-208 (583,19 keV), Ac-288 (911.07 keV) and K-40 (1460,7 keV). Gamma Radioactivity for all of radionuclides from sea water are lower than the threshold value of environmental radioactivity from SK DIRJEN BATAN No 294/DJ/1992. The highest radioactivity of $\gamma$ emitter in sea warer was $K-40$ of 5,798 $\pm 0,537 \mathrm{~Bq} / \mathrm{L}$, whereas the highest permisible concentration was $10^{4} \mathrm{~Bq} / \mathrm{L}$.

\section{PENDAHULUAN}

Semenanjung Muria yang terletak di $\checkmark$ daerah tingkat II Jepara Jawa Tengah, akan selesai membangun Pusat Listrik Tenaga Uap (PLTU) yang diperkirakan tahun 2005 akan mulai beroperasi, dan telah dipilih sebagai lokasi pcmbangunan Pusat Listrik Tenaga Nuklir (PLTN) pertama di Indonesia. Dampak adanya 2
PPL (Pusat Pembangkit Listrik) dan disusul pembangunan industri-industri yang beroperasi di sekitar Muria tersebut, tidak menutup kemungkinan adanya polusi zat radioaktif maupun tidak radioaktif. Sebagai calon lokasi tapak PLTN, di kawasan ini memerlukan pemantauan yang berkesinambungan khususnya guna memperoleh 'base line' radioekologi dan 
radioaktivitas $^{(1,2)}$, Maka perlu sedini mungkin diamati terjadinya polusi lingkungan pada waktu sekarang dan akan datang di sekitar daerah tersebut akibat radioaktif logam berat, beracun dan berbahaya sebelum dan sesudah beroperasinya dua PPL tersebut.

Berdasar SK DIRJEN BATAN No 445/DJ/X/1992, tentang pedoman teknis penyusunan analisis dampak lingkungan untuk rencana pembangunan Pusat Listrik Tenaga Nuklir ${ }^{(2)}$, dan SK DIRJEN BATAN No 446/DJ/X/1994, tentang pedoman teknis Upaya Pcngclolaan Lingkungan (UKL) dan Upaya Pemantauan Lingkungan (UPL) untuk rencana usaha atau kegiatan di bidang nuklir ${ }^{(3)}$, maka perlu dilakukan pengambilan cuplikan lingkungan untuk dianalisis. Pembangunan PLTN diperkirakan mempu-nyai dampak penting terhadap lingkungan, karena itu wajib dilengkapi dengan analisis mengenali dampak lingkungan. Maka rencana lokasi pembangunan PLTN harus dilakukan UKL dan UPL. Salah satu komponen dari komponen lingkungan fisikokimia yang dipilih untuk ditelaah adalah radioaktivitas.

Radioaktivitas adalah proses keadaan perubahan inti atom secara spontan yang disertai radiasi berupa zarah dan atau gelombang elektromagnetik ${ }^{(4,5)}$. Gejala radioaktivitas ini semata-mata ditentukan oleh inti atom yang bersangkutan, tidak dapat dipengaruhi, dipercepat atau diperlambat dengan mengubah kondisi eksternal seperti suhu dan tekanan. Jenisjenis radiasi antara lain adalah sinar $\alpha, \beta, \gamma$, $\chi$ dan sinar neutron.

Penduduk di dunia menerima penyinaran radiasi dari bermacam-macam sumber, sebagian besar berasal dari radiasi alam, yaitu radiasi dari dalam bumi dan kosmik sedangkan sebagian kecil dari sumber buatan manusia. Radioaktivitas alam sudah ada sejak terbentuknya bumi dan alam semesta disebut primordial ini dapat berasal dari deret uranium, thorium, K-40 serta dari luar bumi disebut kosmigetik merupakan radionuklida yang terbentuk sebagai hasil interaksi antara sinar kosmik dengan atom-atom unsur di atmosfer $^{(6,7)}$.

Intensitas radiasi kosmik bervariasi bergantung pada ketinggiannya, garis lintang geografis dan pengaruh medan magnit bumi. Semakin menjauh dari pcrmukaan bumi, penerimaan dosis radiasi kosmik semakin meningkat.

Lingkungan pantai mempunyai karakteristik spesial sebagai tempat akumulasi akhir dari berbagai pencemaran dari pembuangan langsung pada air laut, gejala alam pada atmosfer, maupun sebagai tempat pengendapan material bumi. Di lingkungan laut radionuklida akan diencerkan dan tersebar ke dalam air serta akan berpindah ke dalam biota, sedimen maupun partikel tersuspensi $i^{(7,8)}$. Beberapa faktor yang berpengaruh pada masuknya radionuklida ke dalam massa air, ditentukan oleh faktor penyebaran radionuklida dalam air laut dan pergerakan massa air, sedangkan di perairan muara sungai faktor penyebaran dikontrol oleh interaksi air sungai dengan air laut.

Rantai makanan berperan penting sebagai faktor perunut dan daur radionuklida di perairan laut karena setiap rantai dapat menyerap radionuklida dan proses perpindahan antar rantai memiliki faktor serapan yang relatif tetap ${ }^{(9,10)}$ Organisme yang sering dijadikan bioindikator dalam perairan laut antara lain adalah makroalgae, organisme ini merupakan salah satu spesies yang digunakan secara luas sebagai indikator. Spesies ini terdistribusi luas dari pantai hingga ke laut dalam dan mengakumulasi beberapa radionuklida dengan faktor konsentrasi yang sangat tinggi. Algae di Indonesia secara ekonomi baru dimanfaatkan sebagai bahan makanan dan bahan kosmetik. Organisme lainnya adalah ikan, hewan ini merupakan tingkat organisme tertinggi di laut yang memegang peranan penting dalam rantai makanan di laut, karena banyak dikonsumsi oleh 
manusia. Secara radioekologis-pemantauan radioaktivitas melalui ikan sangat penting karena sebagian besar transfer radionuklida ke manusia dan lingkungan perairan laut berlangsung melalui ikan.

Dalam rangka menunjang pembangunan dengan tetap menjaga keseimbangan lingkungan maka identifikasi radioaktivitas lingkungan di sekitar pesisir Lemahabang dengan tujuan mendapatkan rona awal radioaktivitas pemancar $\gamma$ dan membandingkan dengan radioaktivitas tertinggi yang dijinkan dalam air laut, maka perlu dilakukan pengambilan cuplikan komponen lingkungan algae, ikan kerapu, sedimen dan air laut.

\section{TATA KERJA}

\section{Bahan}

Ikan kerapu, algae, sedimen laut, air laut, $\mathrm{HNO}_{3}$, standar kalibrasi alat Eu-152.

\section{Alat}

Jerigen $5 \mathrm{~L}$, plastik klip tempat sedimen basah/kering dan algae, kotak gabus tempat ikan dibekukan sementara, lumpang stainless steel, ayakan Karl Colb 100 mesh, timbangan analitik, lampu pengering, frezeer, mangkuk porselin, vial pencacahan, alat-alat gelas dan Maestro II EG\&G spektrornetcr $\gamma$ Ortec dengan detektor $\mathrm{Ge}(\mathrm{Li})$.

\section{Pengumpulan cuplikan}

Cuplikan algae, sedimen dan air laut diambil dari sekitar $50 \mathrm{~m}$ dari tepi pantai, atau sekitar 300 meter dari titik nol, sedangkan ikan kerapu diambil sekitar 2 $\mathrm{km}$ dari pantai, di pesisir Lemahabang Muria Jepara Jateng. Sampling dilakukan pada musim hujan. Sedimen diambil sekitar 5 kg ditempatkan dalam plaslik klip, air laut $5 \mathrm{~L}$ dalarn botol plastik yang kemudian ditetesi $\mathrm{HNO}_{3} 5 \mathrm{ml}$, algae $3 \mathrm{~kg}$ ditempatkan dalam plastik klip dan ikan kerapu 3 ekor (2 kg) kemudian dimasukkan dalam kotak gabus yang telah berisi es batu.

\section{Preparasi cuplikan}

Sedimen dijemur dalarn ruangan, setelah kering dibersihkan dari kotoran, ditumbuk dan diayak lolos 100 mesh, diserbasarnakan dan kemudian ditirnbang $200 \mathrm{~g}$ dalam vial pencacahan untuk dicacah. Algae dibersihkan dari kotoran ditimbang dikeringkan dengan bantuan lampu pengering $\left(90^{\circ} \mathrm{C}\right)$ dan ditimbang, ditumbuk dalam lumpang staintess steel dan diayak lolos 50 mesh, diserba-samakan dan kemudian ditimbang 50 g dalam vial pencacahan. Ikan kerapu dipisahkan daging dan bukan daging, daging ikan ditimbang dan dikeringkan, perlakuannya sama dengan algae. Air laut diuapkan dalam cawan (2 liter) dengan pemanas kompor listrik hingga terjadi kristal kemudian dimasukkan dalam vial pencacahan.

Semua cuplikan yang telah dimasukkan dalam vial pencacah, dicacah dengan menggunakan spektrometri $\gamma$ Maestro II EG\&G dengan detektor $\mathrm{Ge}(\mathrm{Li})$, dan semua cuplikan dicacah dengan waktu 7200 detik.

\section{Rumus yang dipakai untuk mengukur radioaktivitas sinar $\gamma$}

Efisiensi detektor $(\mathrm{E}=\%$ ) dengan sumber eksitasi Eu-152 dihitung dengan menggunakan persamaan $(1)^{(4)}$.

$\mathrm{E}=\frac{\mathrm{N}}{\mathrm{A}_{\mathrm{C}} \mathrm{P}_{\mathrm{Y}}}$

dengan:

$\mathrm{A}_{\mathrm{C}}=$ Aktivitas sumber Eu-152 pada saat pengukuran

$\mathrm{P}_{\mathrm{Y}}=$ Probabilitas (intensitas) sinar $\gamma$ Eu-152 Untuk mengukur radioaktivitas y dalam cuplikan ikan kerapu, algae, sedimen laut dan air laut dengan menggunakan persamaan $(2)^{(4,10)}$.

$\mathrm{A}=\frac{\mathrm{N}}{\mathrm{EP}_{\mathrm{Y}} \mathrm{W}}$

dengan

$\mathrm{A}=$ Aktivitas radionuklida yang diperhatikan $\mathrm{Bq} / \mathrm{Kg}$ atau $\mathrm{Bq} / \mathrm{L}$

$\mathrm{W}=$ Berat $(\mathrm{Kg})$ atau volume $(\mathrm{L})$ cuplikan 
Nilai simpangan baku (standar deviasi $=\mathrm{S}$ ) sangat diperlukan dalam pengukuran radioaktivitas, pengukuran dengan tingkat kepercaan $95 \%$, dihitung berdasarkan persamaan (3), sedangkan konsentrasi deteksi terendah (minimum detectable concentration, MDC) dengan menggunakan alat spektrometer $\gamma$ pada percobaan ini dihitung bcrdasarkan persamaan $(4)^{(10)}$.

$\mathrm{S}=\sqrt{\frac{\mathrm{N}_{\mathrm{C}}+\mathrm{N}_{\mathrm{B}}}{\mathrm{T}}}$

$\mathrm{MCD}=\frac{4,66 \cdot \mathrm{S}_{\mathrm{B}}}{\mathrm{EP}_{\mathrm{Y}} \mathrm{W}}$

dengan

$\mathrm{N}=$ Nc \& NB =Laju cacah bersih cuplikan \& laju cacah latar (eps)

$\mathrm{T}=$ Waktu cacah cuplikan = waktu cacah latar

$\mathrm{S}_{\mathrm{B}}=$ Simpangan baku latar

\section{HASIL DAN PEMBAHASAN}

\section{Kalibrasi tenaga dan efesiensi}

Sebelum alat digunakan untuk operasi pencacahan maka harus dikalibrasi tenaga terlebih dahulu dengan menggunakan sumber eksitasi dan diperoleh hubungan garis lurus antara tenaga dan nomor salur, kemudian dibuat kurva kalibrasi tenaga dan persamaan regresi liniernya. Kurva kalibrasi tenaga $(\mathrm{keV})$ ini dapat dilihat pada lampiran Gambar 1. Analisis kuantitatif dengan mengunakan spektrometri gamma membutuh-kan kalibrasi efisiensi. Kalibrasi tenaga maupun kalibrasi efisiensi menggunakan sumber standar Eu-152. Kurva kalibrasi pencacahan terhadap tenaga dapat dilihat pada lampiran Gambar 2. Berdasarkan kurva kalibrasi efisiensi pencacahan pada Gambar 2, maka efisiensi pencacahan pada puncak-puncak tenaga (keV) dapat diketahui.

\section{Identifikasi radionuklida dalam cuplikan}

Identifikasi radionuklida dalam cuplikan ikan kerapu (epeniphelus tauvina), algae hijau dan algae coklat (phaeopyceae), air dan sedimen laut ditampilkan dalam Tabel 1. Identifikasi radionuklida tersebut dilakukan dengan teknik spektrometri gamma dan analisis kualitatif puncak-puncak spektrum. Puncak-puncak tenaga spektrum sinar $\gamma$ karakteristik yang diperoleh ini dicocokkan dengan tabel isotop ${ }^{(11)}$, dengan mengetahui tenaga puncak dapat diidentifikasi radio-nuklida yang terdapat dalam cuplikan yang dicacah, setelah mengetahui radionuklida yang diperhatikan kemudian dapat dilihat besaran intensitasnya. Hasil pengukuran radioaktivitas $\gamma$ dalam cuplikan ikan kerapu, algae, sedimen dan air laut disajikan pada Tabel 2 dan Tabel 3. Hasil yang tersaji dalam Tabel 2 dan 3 merupakan perhitungan radioaktivitas gamma dari radionuklida yang terdeteksi dalam cuplikan. dengan menggunakan persamaan (2). Dari ke 6 radionuklida yang ada, K-40 merupakan radionuklida yang sangat menonjol karena mempunyai aktivitas tertinggi dalam setiap cuplikan. Aktivitas sinar $\gamma$ K-40 yang terbesar terdapat dalam sedimen $762.390 \pm 28.396 \mathrm{~Bq} / \mathrm{Kg}$, sedangkan aktivitas sinar $\gamma$ terkecil adalah radionuklida $\mathrm{Pb}-212$ dengan aktivitas 3,111 $\pm 1,155 \mathrm{~Bq} / \mathrm{Kg}$ terdapat pada daging ikan kerapu. K-40 yang terukur dalam sedimen diperkinikan memang sudah ada di lingkungan tersebut sejak terbentuknya sedimen itu sendiri juga berasal dari tanah atau batuan yang terlarut dan tersuspensi terbawa arus air yang kemudian mengendap bersama-sama sedimen. Radionuklida terukur yang terlarut dalam air laut mempunyai aktivitas sinar $\gamma$ jauh lebih kecil dari pada algae, ikan kerapu maupun sedimen. 
Tabel 1. Hasil identifikasi radionuklida dalam ikan kerapu. algae hijau dan algae coklat, air dan sedimen laut

\begin{tabular}{|c|c|c|c|c|}
\hline $\begin{array}{c}\text { Radio } \\
\text { nuklida }\end{array}$ & $\begin{array}{c}\text { Tenaga } \\
(\mathrm{keV})\end{array}$ & Sumber & $\begin{array}{c}\text { Umur } \\
\text { paro }\end{array}$ & $\begin{array}{c}\text { Intesitas } \\
\gamma\end{array}$ \\
\hline Ra-226 & 186.52 & Deret U-238 & 1.600 th & 0.0351 \\
Pb-212 & 238.75 & Deret Th-232 & 10.64 jam & 0,4460 \\
Pb-214 & 295.94 & Deret U-233 & 3.1 menil & 0,1970 \\
TI-20S & 583.19 & Deret Th-232 & 26.8 menit & 0,8577 \\
Ac-228 & 911.07 & Deret Th-232 & 6.13 jam & 0.2770 \\
K-40 & 1460.8 & Alam & $1,27.10^{9}$ th & 0.1067 \\
\hline
\end{tabular}

Hasil pengukuran radioaktivitas $\gamma$ dalam air laut dan konsentrasi/kadar tertinggi yang dijinkan (KTD), disajikan dalam Tabel 3. Konsentrasi yang diperhatikan dalam Tabel. 3 masih jauh di bawah batas kadar tertinggi yang diijinkan menurut keputusan DIRJEN BATAN No
294/DJ/I992(12). Hal ini menunjukkan bahwa secara radiologis air laut masih di bawah ambang batas yang diperkenankan, sehingga radioaktivitas $\gamma$ yang tersajikan merupakan kondisi latar di sekitar pengambilan cuplikan.

Hasil pengukuran radiaktivitas $\gamma$ pada Tabel 2 dan 3 nantinya dibandingkan dengan pengambilan cuplikan dimusim kemarau, selanjutnya pemantauan radioaktivitas biota perairan setelah beroperasinya PLTU Tanjungjati B, yang diperkirakan beroperasi tahun 2005. Hasil dari pengukuran radioaktivitas ini selanjutnya tersusun data rona awal (base line) radioaktivitas biota di daerah calon tapak PLTN Ujung Lemahabang, yang mengakomodasikan data lingkungan terkini, dalam rangka mendukung izin tapak dan AMDAL PLTN.

Tabel 2. Hasil pengukuran radioaktivitas $\gamma$ dalam cuplikan ikan kerapu, algae. sedimen air laut $(\mathrm{Bq} / \mathrm{Kg})$

\begin{tabular}{|l|l|l|l|l|}
\hline \multirow{2}{*}{ Radionuklida } & \multicolumn{4}{|c|}{ Aktivitas $\gamma(\mathrm{Bq} / \mathrm{Kg})$ atau $(\mathrm{Bq} / \mathrm{L})$} \\
\cline { 2 - 5 } & \multicolumn{1}{|c|}{ Ikan } & \multicolumn{1}{|c|}{ Algae hijau } & \multicolumn{1}{c|}{ Sedgae coklat } & \multicolumn{1}{c|}{ Sedimen } \\
\hline Ra-226 & $5,556 \pm 0,909$ & $30,397 \pm 3,224$ & $36,091 \pm 3,861$ & $134,371 \pm 9,893$ \\
Pb-212 & $3,111 \pm 1,155$ & $3,449 \pm 4,344$ & $31,509 \pm 4,95$ & $20,492 \pm 2,832$ \\
Pb-214 & $4,761 \pm 0,268$ & $9,362 \pm 0,345$ & $14,425 \pm 2,111$ & $301,15 \pm 12,644$ \\
Tl-208 & $4,205 \pm 1,044$ & $14,065 \pm 0,494$ & $32,065 \pm 1,071$ & $37,147 \pm 3,25$ \\
Ac-228 & $4,158 \pm 1,256$ & $4,644 \pm 2,718$ & $10,113 \pm 2,862$ & $138,09 \pm 11,43$ \\
K-40 & $41,869 \pm 9,921$ & $317,053 \pm 13,86$ & $338,50 \pm 5,5$ & $762,39 \pm 28,396$ \\
\hline
\end{tabular}

Tabel 3. Hasil pengukuran radioaktivitas $\gamma$ dalam air laut dan konsentrasi/ kadar tertinggi yang dijinkan (KTD) Bq/L

\begin{tabular}{|c|c|c|}
\hline \multirow{2}{*}{ Radionuklida } & \multicolumn{2}{|c|}{ Aklivilas y (BQ/L) } \\
\cline { 2 - 3 } & Terukur & KTD \\
\hline Ra-226 & $1,528 \pm 0,154$ & 40 \\
Pb-212 & $0,0349 \pm 0,018$ & 4 \\
Pb- 214 & $0,0929 \pm 0,017$ & 4 \\
Tl-208 & $0,428 \pm 0,272$ & 3.000 \\
Ac-228 & $1,484 \pm 0,272$ & 3.000 \\
K-40 & $11,798 \pm 0,53$ & 10.000 \\
\hline
\end{tabular}

Presisi dan konsentrasi deteksi terkecil (minimum detectable concentration, MDC)

Tabel 4 merupakan hasil pengukuran simpangan baku, presisi dan konsentrasi deteksi terkecil (minimum detectable concentration, MDC). Simpangan baku dihitung dengan persamaan (3) dengan tingkat kepercayaan $95 \%$, hasil yang terukur setiap radionuklida berbeda. Simpangan baku sering juga dihitung dengan bantuan komputer maupun kalkulator, khususnya untuk konsentrasi dibawah 100 ppm dan pengulangan pengukuran paling tidak 5 $\mathrm{kali}^{(\mathrm{t})}$. Presisi merupakan hasil pengukuran yang menghasilkan ketelitian, presisi dari 
perhitungan hasil simpangan baku atau standar deviasi dibagi dengan pencacahan cuplikan radionuklidanya. Presisi semakin kecil maka pengukuran radionuklida akan lebih teliti dan presisi dipengaruhi akan besarnya radionuklida yang terukur, semakin besar radionuklida yang terukur maka simpangan bakunya akan semakin kecil, hal ini berarti presisinya akan semakin kecil juga.

Konsentrasi deteksi terkecil (MDC) untuk setiap radionuklida pada Tabel 4, mempunyai harga yang berbeda-beda, dapat dibandingkan antara radionuklida K40 dengan TI-208, untuk radionuklida Tl208 terlihat konsentrasi deteksi terkecil $0,939 \mathrm{~Bq} / \mathrm{Kg}$, untuk cuplikan sedimen laut dan yang terbesar adalah radionuklida K-40 konsentrasi deteksi terkecil 20,492 Bq/Kg. Konsentrasi deteksi terkecil dengan menggunakan persamaan (4), dipengaruhi oleh probabilitas atau intensitas sinar gamma dan efisiensi detektor pencacahan. Intensitas TI-208 adalah 85,77 \%, dapat dilihat pada Tabel 1 dan efisiensi sebesar $0,5492 \%$, dapat dilihat pada lampiran Gambar 1, sedangkan K-40 intensitas 10,67 \% dan efisiensinya 0,1929 \%. Pengaruh dari intensitas dan efisiensi akan mempengaruhi MCD, semakin kecil harga intensitas dan efisiensi maka MCD akan makin besar.

Tabel 4. Pengukuran simpangan baku, presisi dan konsentrasi deteksi terendah untuk cuplikan sedimen laut.

\begin{tabular}{|c|c|c|c|}
\hline $\begin{array}{c}\text { Radionu } \\
\text { klida }\end{array}$ & $\begin{array}{c}\text { Simpangan } \\
\text { baku }\end{array}$ & $\begin{array}{c}\text { Presisi } \\
(\%)\end{array}$ & $\begin{array}{c}\text { MDC } \\
(\mathrm{Bq} / \mathrm{Kg})\end{array}$ \\
\hline Ra-226 & 9,893 & 7,362 & 2,352 \\
$\mathrm{~Pb}-212$ & 2,832 & 13,820 & 1,333 \\
$\mathrm{~Pb}-214$ & 12,644 & 4,198 & 3,748 \\
$\mathrm{TI}-208$ & 3,25 & 8,74 & 0,939 \\
Ac-228 & 11,430 & 8,277 & 3,364 \\
K-40 & 28,396 & 3,724 & 20,492 \\
\hline
\end{tabular}

\section{KESIMPULAN}

1. Identifikasi radionuklida pemancar $\gamma$ yang terdapat dalam sedimen, air laut, ikan kerapu dan algae ada 6 jenis radionuklida yaitu Ra-226 (186,52 keV), Pb-212 (238,75 keV), Pb-214 (395,94 $\mathrm{keV}), \quad$ TI-208 (583,19 keV), Ac-288 (911,07 keV) dan K-40 (1460,7 keV).

2. Radionuklida pemancar $\gamma$ dalam air laut untuk semua radionuklida masih jauh dibawah konsentrasi tertinggi yang dijinkan menurut SK DIRJAN BATAN No 294fDJ/1992, hal ini menunjukkan bahwa secara radiologis air laut di pesisir Lemahabang Jepara masih dibawah ambang yang diperkenankan.

3. Konsentrasi deteksi terendah (minimum detectable concentration, MDC) pada cuplikan sedimen laut untuk radionuklida yang diperhatikan sekitar 0,939 $\mathrm{Bq} / \mathrm{Kg}$ sampai dengan 20,492 Bq/Kg.

\section{DAFFAR PUSTAKA}

1. SUKIRNO., SUDARMADJI., "Pengukuran Raioaktivitas Gamma, Beta dan Identifikasi Radionuklida dalam Sedimen dan Air Sungai"., Prosiding, PPl, .P3TM BAT AN., Y ogyakarta (2001)

2. BATAN., Surat Keputusan DIRJEN BATAN No 445/DJ/X/1992., Jakarta (1992)

3. BATAN., Surat Keputusan DIRJEN BATAN No 446/DJ/X/1992., Jakarta (1994)

4. SUSETYO, W., Spektrometri Gamma., Gajah Mada University Press., Yogyakarta (1988)

5. WARDANA.W.A., Teknik Radioaktivitas Lingkungan., Andi Yogyakarta (1994)

6. ISMONA, A., SUTARMAN dan NAREH, M., Upaya Pemantauan Radiasi dan Radioaktivitas Lingkungan"., PIKRL., BATAN., Jakarta ( 1993)

7. Analisis Offer. 
8. IAEA., Reference Methods for Marine Radioactivity Studies., Teclmical report Series No 118., Vienna (1970)

9. IAEA., Guidelines for Agricultural Release of Radionuclides., Vienna (1994)

10. DAHLGAARD, H., Marine Radioecology, Nordic Radiology: Compendium for a Nordic Postgraduate Course in General Radioecology., Land Sweden (1991)
11. IAEA., Measurement of Radionuclides in Food end The Environment., A Guide Book., Technical Report Series No 295,., Vienna (1989)

12. ERDTMANN. G., Neutron Activation Tables., New York (1989).

13. BATAN., Surat Keputusan DIRJEN BATAN No 294/DJ/X/1992., Jakarta (1992).

\section{LAMPIRAN}

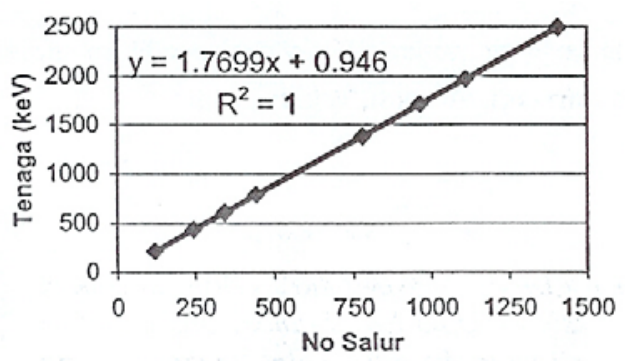

Gambar 1. Kalibrasi tenaga (keV) terhadap nomor salur

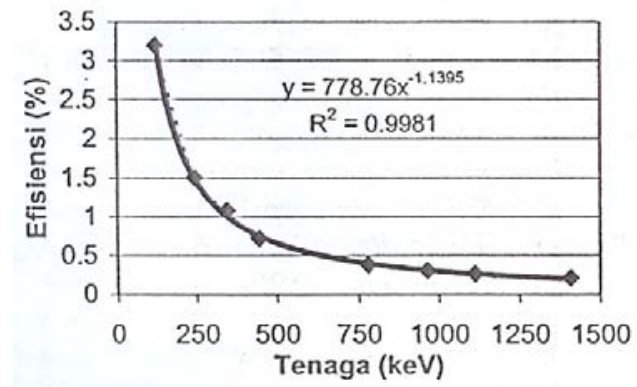

Gambar 2. Kalibrsi efisiensi terhadap tenaga sinar $\gamma(\mathrm{keV})$ 